Supplementary Information for

\title{
High-Valent Iron Redox-Mediated Photoelectrochemical Water Oxidation
}

Tae Hwa Jeon, ${ }^{1,2}$ Seungmok Han, ${ }^{1}$ Bupmo Kim, ${ }^{1}$ Cheolwoo Park, ${ }^{3}$ Wooyul Kim, ${ }^{4}$ Hyunwoong Park, ${ }^{5, *}$ and Wonyong Choi $^{1, *}$

${ }^{I}$ Division of Environmental Science and Engineering, Pohang University of Science and Technology (POSTECH), Pohang 37673, Korea

${ }^{2}$ Department of Civil and Environmental Engineering, Rice University, Houston, TX 77005, U.S.A.

${ }^{3}$ Department of Energy Science, Sungkyunkwan University, Suwon 16419, Korea

${ }^{4}$ Department of Chemical and Biological Engineering, Sookmyung Women's University, Seoul 04310, Republic of Korea

${ }^{5}$ School of Energy Engineering, Kyungpook National University, Daegu 41566, Korea

*To whom correspondence should be addressed:

(H.P.) E-mail: hwp@knu.ac.kr; Tel: +82-53-950-8973

(W.C.) E-mail: wchoi@postech.edu; Tel: +82-54-279-2283

Total number of pages: 21

Number of Figures: 15 


\section{Methods}

\section{Materials and electrodes}

All chemicals were used as received without further purification. $\mathrm{NaNO}_{3}$ (Aldrich, $99.99+\%$ ) and $\mathrm{Fe}\left(\mathrm{NO}_{3}\right)_{3} \cdot 9 \mathrm{H}_{2} \mathrm{O}$ (Kanto Chemical, $>99.0 \%$ ) were used for preparing the electrolyte. Other chemicals used in this study include $\mathrm{FeCl}_{3} \cdot 6 \mathrm{H}_{2} \mathrm{O}$ (Aldrich, ACS Reagent, 97\%), $\mathrm{NaCl}$ (Aldrich, BioXtra, $>95 \%$ ), $\mathrm{Fe}_{2}\left(\mathrm{SO}_{4}\right)_{3} \cdot x \mathrm{H}_{2} \mathrm{O}$ (Aldrich, Reagent Plus, $>99.9 \%$ ), $\mathrm{Na}_{2} \mathrm{SO}_{4}$ (Alfa Aesar, >99.0\%), $\mathrm{HNO}_{3}$ (Aldrich, ACS Reagent, 69-70\%), NaOH (Fluka, Standard Solution, 8 M), and polyethylene glycol (PEG) \#20,000 (Samchun Chemicals). Solutions were prepared using ultrapure deionized water $(18.3 \mathrm{M} \Omega \mathrm{cm}$, Barnstead EASYpure RO system). Tungsten trioxide (Aldrich, tungstic anhydride, average particle size $<100 \mathrm{~nm}$ ) was used as a photocatalyst. The $\mathrm{WO}_{3}$ films were prepared onto fluorine-doped tin oxide substrates (FTO, Pilkington, $15 \Omega /$ square) using a doctor-blade method as reported elsewhere. ${ }^{1}$ Briefly, $1.6 \mathrm{~g} \mathrm{WO}_{3}$ powder was mixed with $1 \mathrm{~mL}$ carbowax solution $(1 \mathrm{~g}$ PEG : $1 \mathrm{~mL}$ DI water mixture) and ground in a mortar for 10 min until it became a homogeneous and sticky mixture. Then an aliquot of the mixture was dropped and spread over the FTO with a geometric area of $4.0 \mathrm{~cm}^{2}$. The films were dried in air and annealed at $450{ }^{\circ} \mathrm{C}$ for $30 \mathrm{~min}$.

\section{Photoelectrochemical measurements and analyses}

The PEC behavior of the as-synthesized $\mathrm{WO}_{3}$ film was examined in a customized threecompartment cell containing $0.5 \mathrm{M} \mathrm{NaNO}_{3}$ adjusted to $\mathrm{pH} 3$ by $\mathrm{HNO}_{3}$ or $\mathrm{NaOH}$. A Pt wire and an $\mathrm{Ag} / \mathrm{AgCl}(3 \mathrm{M} \mathrm{KCl})$ electrode were used as a counter and reference electrode, respectively. All compartments were separated by glass frits. The concentration of $\mathrm{Fe}\left(\mathrm{NO}_{3}\right)_{3} \cdot 9 \mathrm{H}_{2} \mathrm{O}$ varied 1-100 mM. The light source was an in-built ozone-free 150-W Xe arc lamp (model LS150, Abet Technologies LS1-10500) and the incident light intensity was adjusted to $300 \mathrm{~mW} \mathrm{~cm}$. 
For linear sweep voltammograms (LSVs), the potential of the working electrode was swept from 0.02 to $1.52 \mathrm{~V}$ (vs. $\mathrm{Ag} / \mathrm{AgCl}$ ) at a scan rate of $50 \mathrm{mV} \mathrm{s}^{-1}$ in the dark or under irradiation. For bulk PEC reactions, a constant potential between 0.65 and $1.50 \mathrm{~V}$ (vs. $\mathrm{Ag} / \mathrm{AgCl}$ ) was applied to the working electrode. For comparison, the aforementioned experiments were also performed without any potential bias to drive PC reactions. Hereafter, "V vs. $\mathrm{Ag} / \mathrm{AgCl}$ " was converted to "V vs. RHE" by the following equation: $\mathrm{V}_{\mathrm{RHE}}=\mathrm{V}_{\mathrm{Ag} / \mathrm{AgCl}}+0.197+0.059 \times \mathrm{pH}$.

Prior to irradiation, the electrolytes were purged with Ar gas for 30 min to remove dissolved and headspace $\mathrm{O}_{2}$. While applying a constant potential to $\mathrm{WO}_{3}$ under irradiation, 100 $\mu \mathrm{L}$ of gas samples were intermittently withdrawn from the headspace of the $\mathrm{WO}_{3}$ compartment with a gastight glass syringe (Hamilton 81030). Then, the amounts of evolved $\mathrm{O}_{2}$ were quantified using a gas chromatograph (GC, HP6890A) equipped with a thermal conductivity detector (TCD) and a $5 \AA$ molecular sieve column. The Faradaic efficiency (FE) for $\mathrm{O}_{2}$ evolution was estimated by the following equation: $\mathrm{FE}=4 F \mathrm{n} / \mathrm{Q}_{\mathrm{ph}} \times 100 \%$, where $F$ is the Faraday constant $\left(96,485 \mathrm{C} \mathrm{mol}^{-1}\right), \mathrm{n}$ is the measured amount of evolved $\mathrm{O}_{2}(\mathrm{~mol})$, and $\mathrm{Q}_{\mathrm{ph}}$ is the integrated photocharge (C).

High-valent iron species produced during the PEC reactions was quantified using a selective oxidation reaction of dimethyl sulfoxide (DMSO) to dimethyl sulfone $\left(\mathrm{DMSO}_{2}\right)$. The concentrations of DMSO and $\mathrm{DMSO}_{2}$ were analyzed by ${ }^{1} \mathrm{H}$ nuclear magnetic resonance (NMR, Bruker Avance III HD) $500 \mathrm{MHz}$ spectroscopy. All experiments were performed in deuterated water $\left(\mathrm{D}_{2} \mathrm{O}\right)$ to prevent the interference from protons of water. An aliquot $(20 \mu \mathrm{L})$ was withdrawn and diluted with $\mathrm{D}_{2} \mathrm{O}(580 \mu \mathrm{L})$, which was transferred to a $5 \mathrm{~mm}$-standard NMR tube for measurements. Besides, $\mathrm{Fe}^{2+}$ ions produced during the $\mathrm{PC}$ and $\mathrm{PEC}$ reactions were quantified using the 1,10-phenanthroline method. ${ }^{2}$ Typically, an aliquot $(0.1 \mathrm{~mL})$ was withdrawn and diluted with DI water $(1.4 \mathrm{~mL})$, to which 1,10 -phenanthroline $(2 \%, 1.5 \mathrm{~mL})$ 
and ammonium acetate $(2 \mathrm{~mL})$ were added. After $1 \mathrm{~h}$ in dark, the absorbance of the solution was measured at $\lambda=510 \mathrm{~nm}$ using a UV-Vis absorption spectrophotometer (Libra S22, Biochrom).

\section{Surface characterization}

The surface morphologies of as-synthesized and used $\mathrm{WO}_{3}$ samples were analyzed using high resolution field emission scanning electron microscopy (FE-SEM, JOEL JSM7800F PRIME) with dual energy dispersive X-ray spectroscopy (EDS) at National Institute for Nanomaterials Technology (Pohang, Korea). X-ray diffraction (XRD) patterns of the samples were measured using $\mathrm{Cu} \mathrm{K \alpha}$ radiation (RIGAKU D MAX 2500). X-ray photoelectron spectroscopy (XPS) was analyzed using monochromated Al Ka radiation as an X-ray source $(1486.6 \mathrm{eV})$ at Korea Basic Science Institute (Busan Center, Korea). X-ray absorption fine structure (XAFS) spectroscopy was analyzed using 8C nano-probe XAFS beamline (BL8C) at Pohang Light Source (PLS-II). W L3-edge XAFS spectra were obtained by fluorescence mode, and processed with ATHENA software program. Nuclear Magnetic Resonance (NMR) spectroscopy was analyzed using ${ }^{1} \mathrm{H}$ NMR $500 \mathrm{MHz}$ spectrometer (Bruker Avance III HD).

\section{In-situ transient absorption spectroscopy}

The time-resolved absorption spectroscopy with transmission detection was carried out with the third harmonic of the Nd:YAG laser $(10 \mathrm{~Hz}, \mathrm{NT} 342 \mathrm{~A}$, EKSPLA, $\lambda=355 \mathrm{~nm}(1$ $\mathrm{mJ}$ per pulse)) as an excitation source during the $\mathrm{PC}$ and $\mathrm{PEC}$ reactions with the Xe lamp (continuous wave, $300 \mathrm{~W}$, Newport) as a probe light source. The as-synthesized transparent $\mathrm{WO}_{3}$ electrodes were immersed in $0.5 \mathrm{M} \mathrm{NaNO}_{3}\left(\mathrm{pH}\right.$ 3) with or without $1 \mathrm{mM} \mathrm{Fe}^{3+}$ in a Pyrex glass cell equipped with a quartz window for light penetration. The transmitted probe light was focused on a monochromator (Princeton Instruments, Acton SpectraPro SP-2300). The output 
of the monochromator was monitored using a photomultiplier Tube (PDS-1, Dongwoo Optron). The transient signals were passed through an amplifier (SR445A, Stanford Research Systems) and then recorded by a digital oscilloscope (350 MHz, MDO4034C, Tektronix). The transient absorption spectra of $\mathrm{WO}_{3}$ films with $\mathrm{Fe}^{3+}$ were subtracted from those without $\mathrm{Fe}^{3+}$ under $\mathrm{PC}$ and PEC (1.88 $\left.\mathrm{V}_{\mathrm{RHE}}\right)$ conditions. 

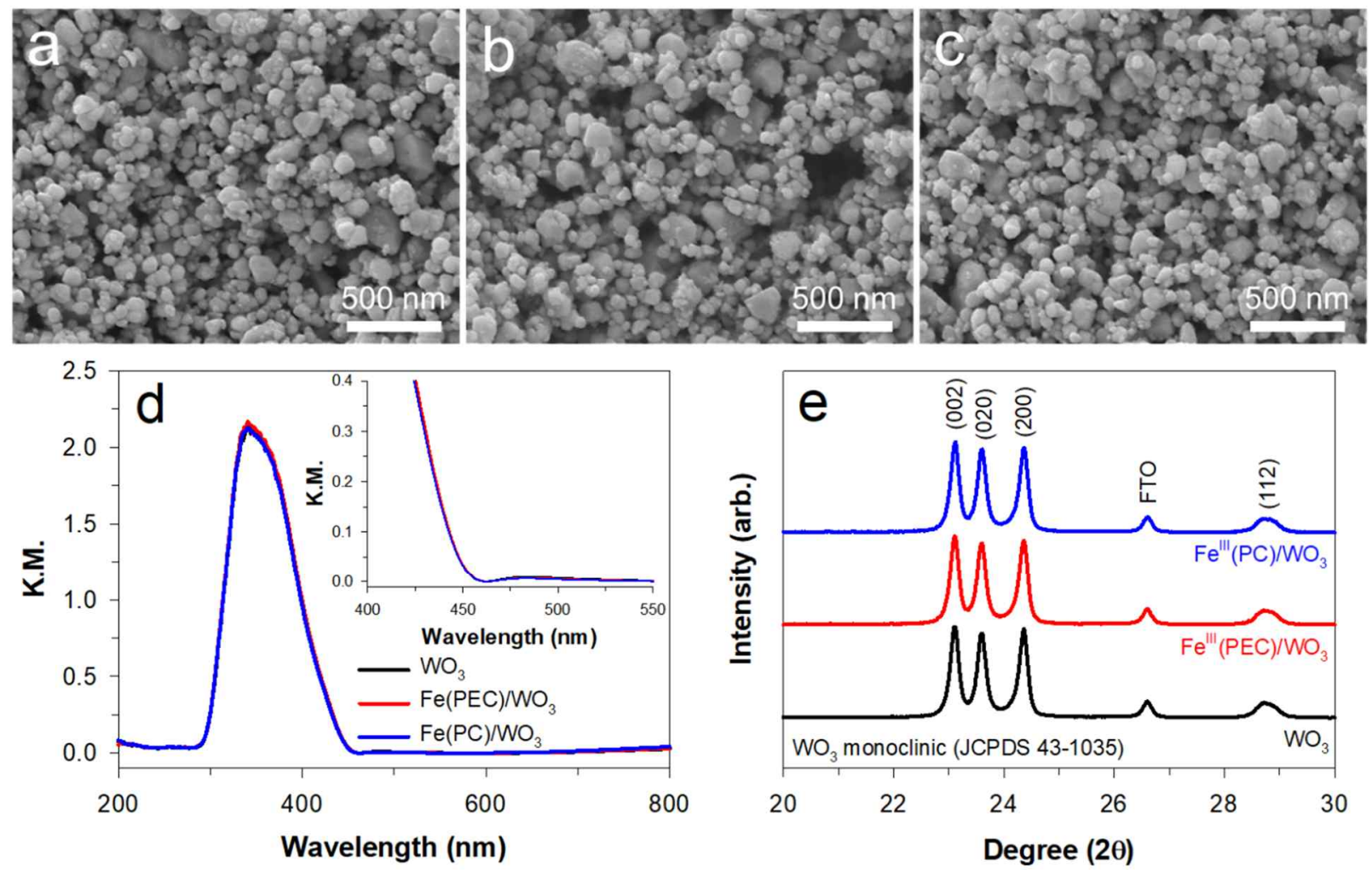

Figure S1. SEM images of (a) an as-synthesized $\mathrm{WO}_{3}$ film, and (b and c) used $\mathrm{WO}_{3}$ films for photoelectrochemical (PEC) and photocatalytic (PC) reactions with $\mathrm{Fe}(\mathrm{III})\left(\mathrm{Fe}{ }^{\mathrm{III}}(\mathrm{PEC}) / \mathrm{WO}_{3}\right.$ and $\mathrm{Fe}^{\mathrm{III}}(\mathrm{PC}) / \mathrm{WO}_{3}$, respectively). (d and e) DRS spectra and XRD patterns, respectively, of $\mathrm{WO}_{3}, \mathrm{Fe}^{\mathrm{III}}(\mathrm{PEC}) / \mathrm{WO}_{3}$, and $\mathrm{Fe}^{\mathrm{III}}(\mathrm{PC}) / \mathrm{WO}_{3}$ films. 


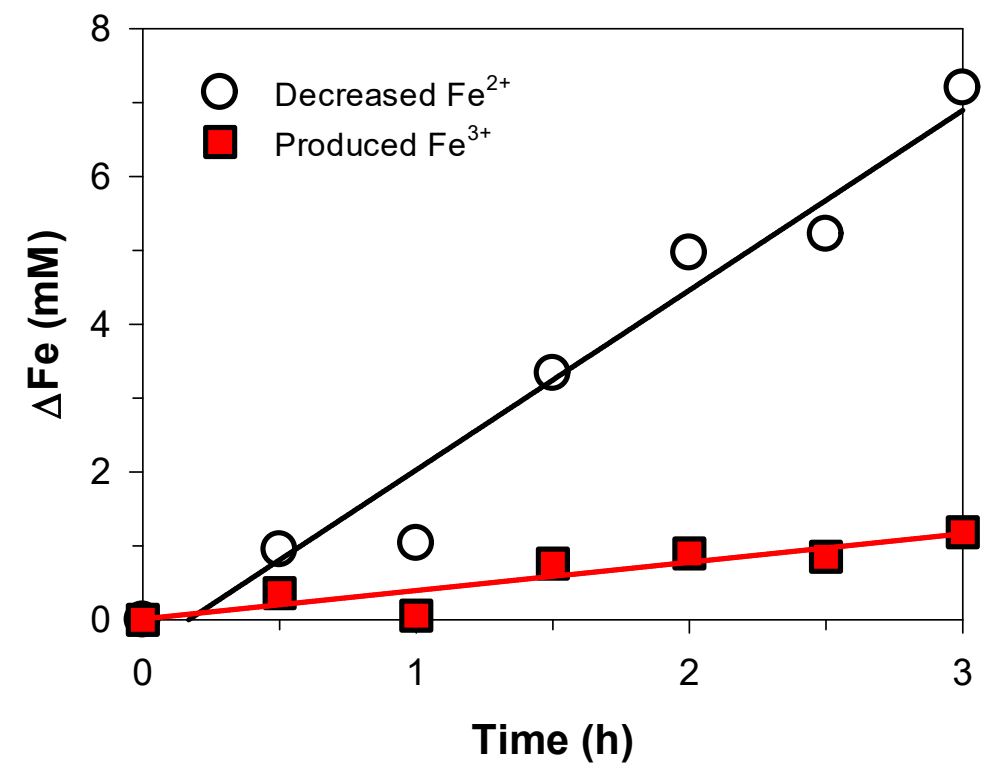

Figure S2. Changes in the amounts of aqueous $\mathrm{Fe}^{2+}$ and $\mathrm{Fe}^{3+}$ ions during the PEC reactions with $\mathrm{Fe}^{2+}(50 \mathrm{mM})$ at $1.23 \mathrm{~V}_{\mathrm{RHE}}$. 


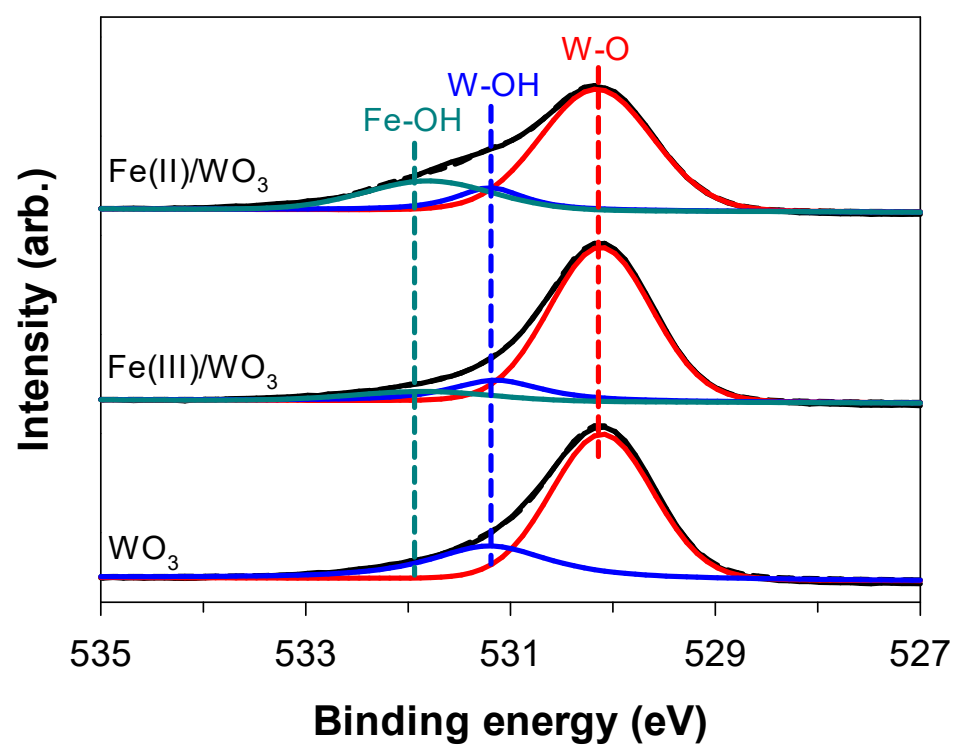

Figure S3. O 1s XPS spectra for $\mathrm{WO}_{3}$ only, $\mathrm{WO}_{3}$ with $\mathrm{Fe}^{2+}\left(\mathrm{Fe}(\mathrm{II}) / \mathrm{WO}_{3}\right)$, and $\mathrm{WO}_{3}$ with $\mathrm{Fe}^{3+}$ $\left(\mathrm{Fe}(\mathrm{III}) / \mathrm{WO}_{3}\right)$ after PEC reactions. 

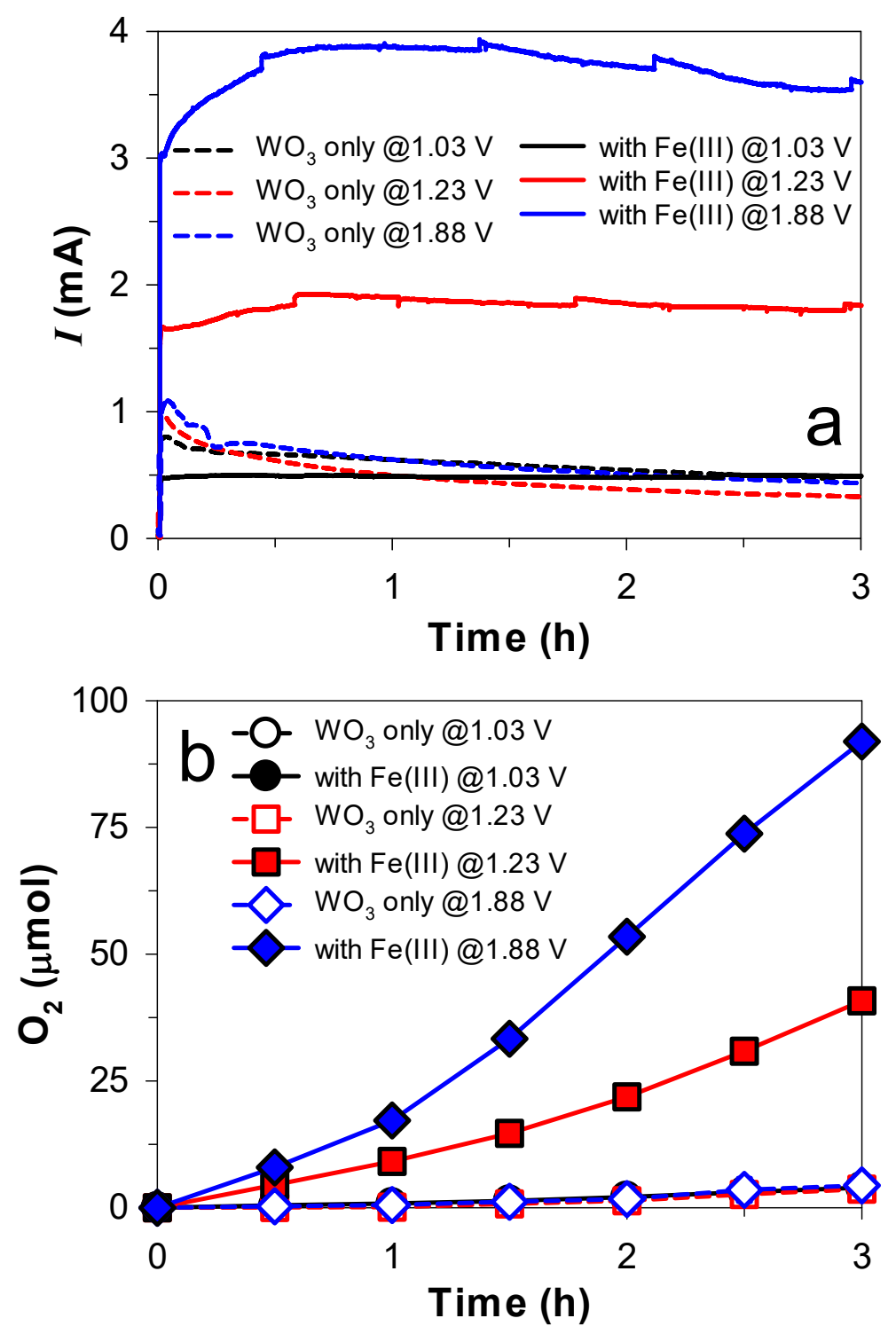

Figure S4. Photoelectrochemical water oxidation activities of $\mathrm{WO}_{3}$ films in aqueous $\mathrm{NaNO}_{3}$ solutions $(0.5 \mathrm{M})$ at $\mathrm{pH} 3$ in the absence and presence of $50 \mathrm{mM} \mathrm{Fe}^{3+}$ under different potential bias $\left(\mathrm{E}=1.03,1.23\right.$, and $\left.1.88 \mathrm{~V}_{\mathrm{RHE}}\right)$ : (a) Photocurrent-time profiles and (b) concurrent $\mathrm{O}_{2}$ evolutions. Faradaic efficiencies for $\mathrm{O}_{2}$ evolutions are shown in Figure 2. 

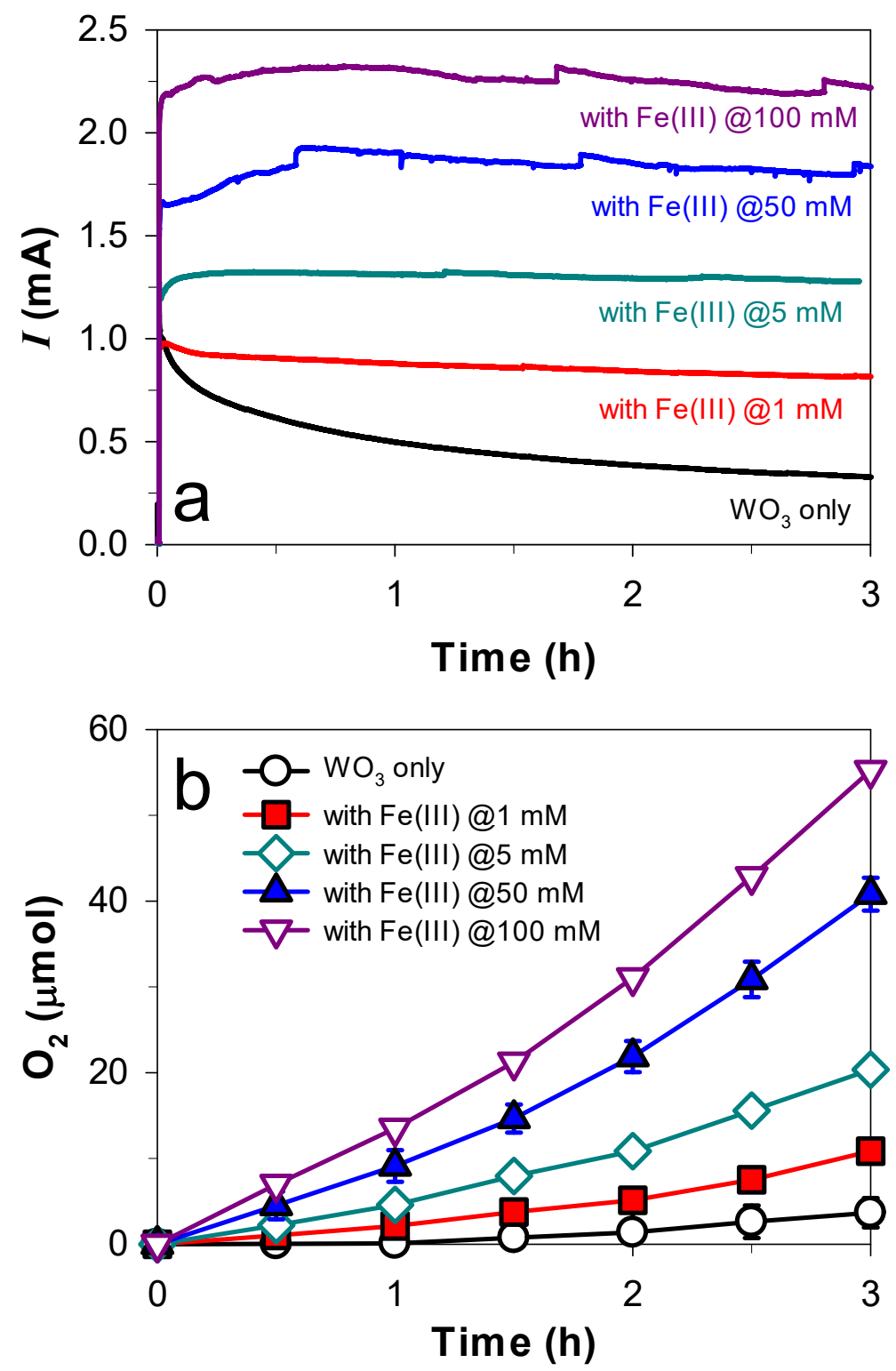

Figure S5. Photoelectrochemical water oxidation activities of $\mathrm{WO}_{3}$ films in aqueous $\mathrm{NaNO}_{3}$ solutions $(0.5 \mathrm{M})$ at $\mathrm{pH} 3$ with varying concentrations of $\mathrm{Fe}^{3+}(0-100 \mathrm{mM}) . \mathrm{E}=1.23 \mathrm{~V}_{\text {RHE. }}$ (a) Photocurrent-time profiles and (b) concurrent $\mathrm{O}_{2}$ evolutions. Faradaic efficiencies for $\mathrm{O}_{2}$ evolutions are shown in Figure 2. $\mathrm{WO}_{3}$ only refers to $0 \mathrm{mM} \mathrm{Fe}^{3+}$. 


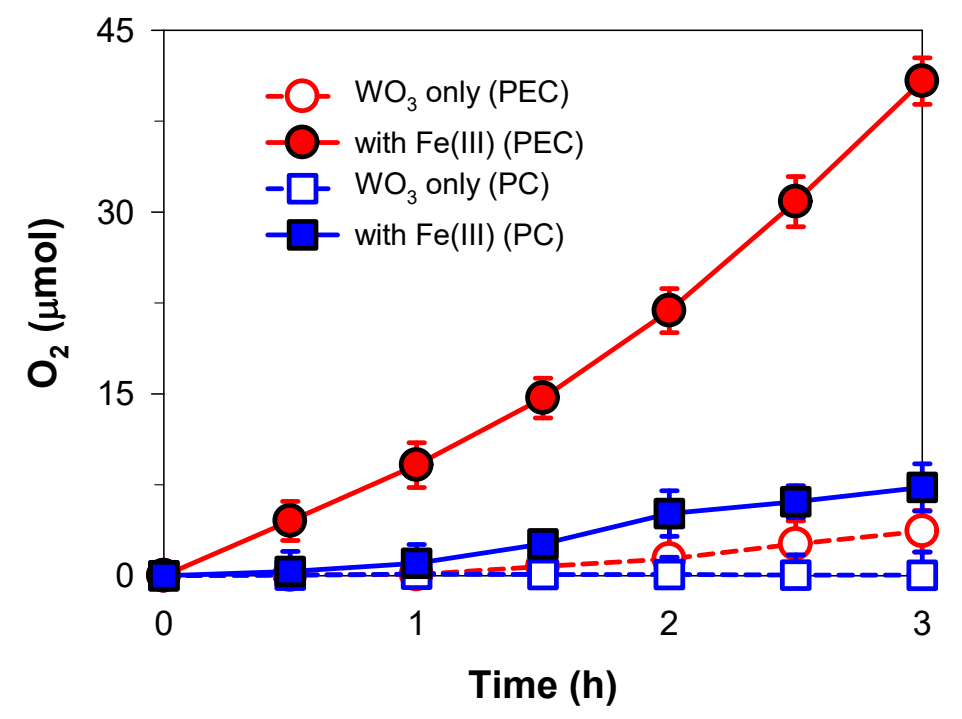

Figure S6. Photoelectrochemical (PEC, biased at 1.23 $\mathrm{V}_{\mathrm{RHE}}$ ) and photocatalytic (PC, bias-free) water oxidation activities of $\mathrm{WO}_{3}$ films in aqueous $\mathrm{NaNO}_{3}$ solutions $(0.5 \mathrm{M})$ at $\mathrm{pH} 3$ in the absence and presence of $50 \mathrm{mM} \mathrm{Fe}^{3+}$. The results of PEC reactions are also shown in Figure $1 \mathrm{c}$. 


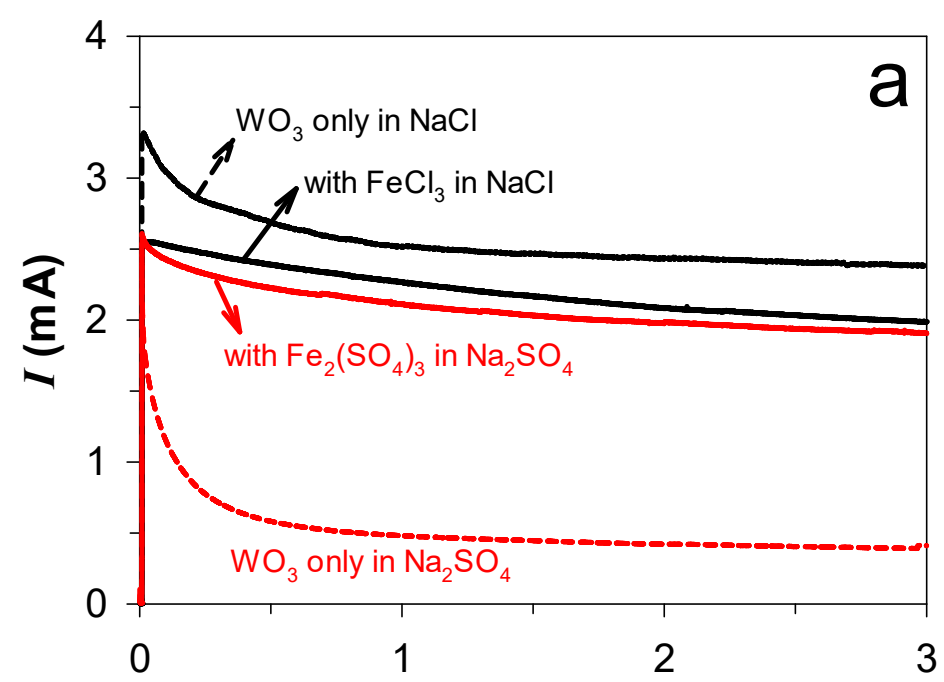

Time (h)

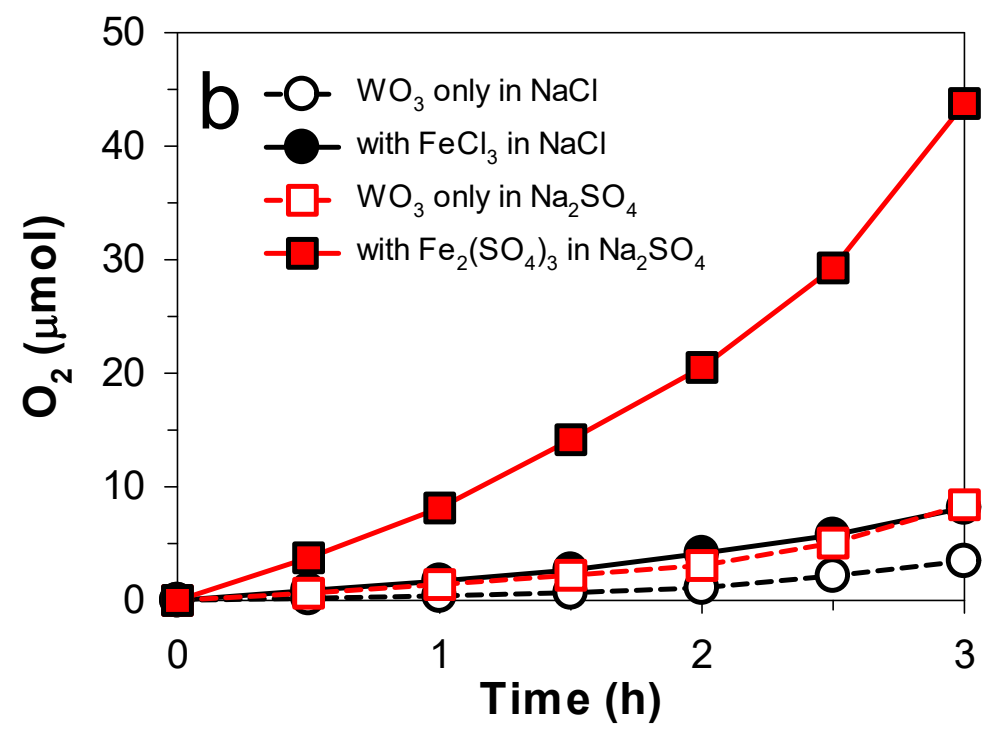

Figure S7. Photoelectrochemical water oxidation activities of $\mathrm{WO}_{3}$ films biased at $1.23 \mathrm{~V}_{\mathrm{RHE}}$ in aqueous $\mathrm{NaCl}$ and $\mathrm{Na}_{2} \mathrm{SO}_{4}$ solutions $(0.5 \mathrm{M})$ at $\mathrm{pH} 3$ in the absence and presence of $50 \mathrm{mM}$ $\mathrm{Fe}^{3+}$ (i.e., $\mathrm{FeCl}_{3}$ or $\left.\mathrm{Fe}_{2}\left(\mathrm{SO}_{4}\right)_{3}\right)$. (a) Photocurrent-time profiles and (b) concurrent $\mathrm{O}_{2}$ evolutions. Faradaic efficiencies for $\mathrm{O}_{2}$ evolutions are shown in Figure 2. 

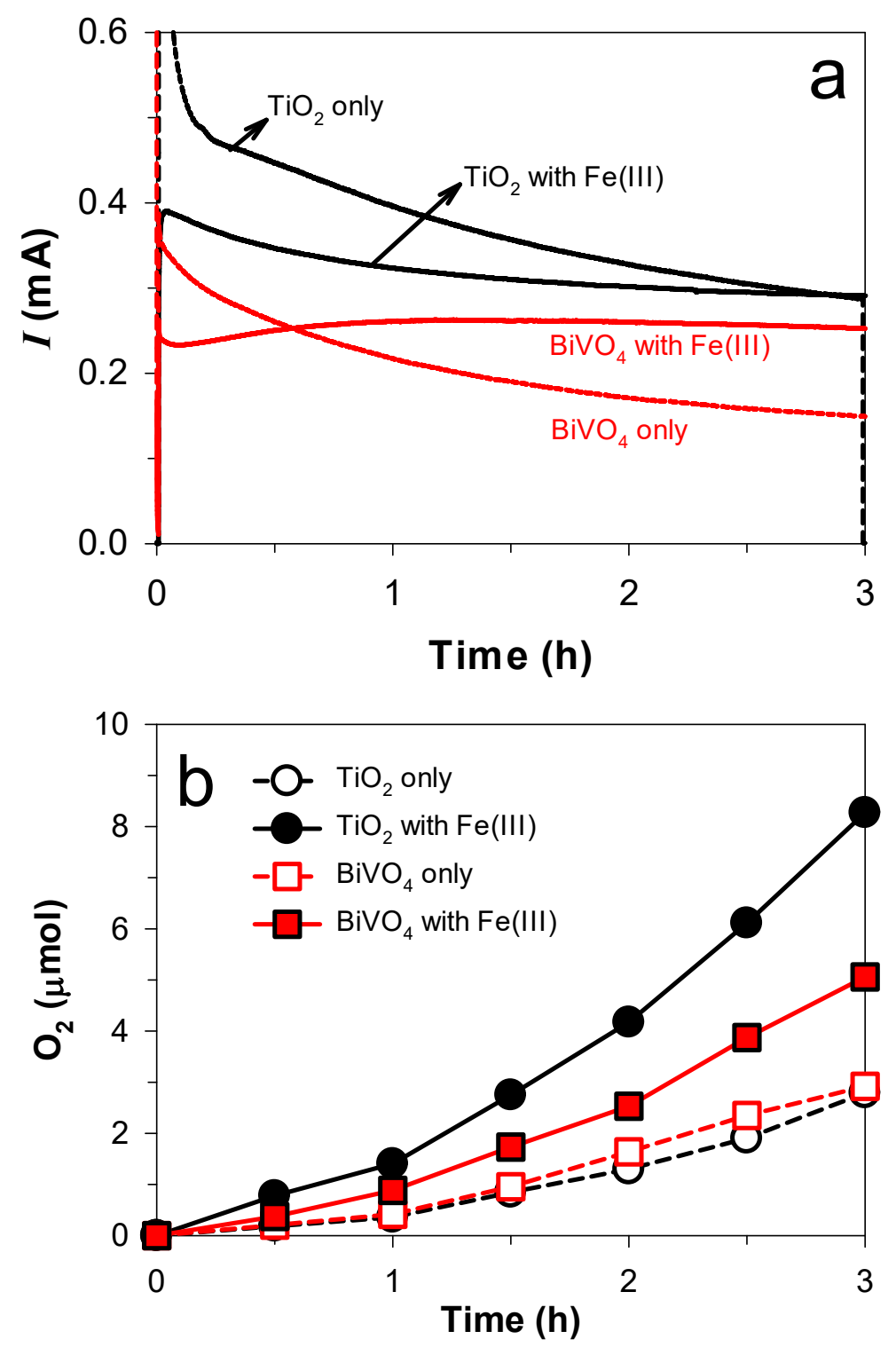

Figure S8. Photoelectrochemical water oxidation activities of $\mathrm{TiO}_{2}$ and $\mathrm{BiVO}_{4}$ films biased at $1.23 \mathrm{~V}_{\text {RHE }}$ in aqueous $\mathrm{NaNO}_{3}$ solutions $(0.5 \mathrm{M})$ at $\mathrm{pH} 3$ in the absence and presence of $50 \mathrm{mM}$ $\mathrm{Fe}^{3+}$. (a) Photocurrent-time profiles and (b) concurrent $\mathrm{O}_{2}$ evolutions. Faradaic efficiencies for $\mathrm{O}_{2}$ evolutions are shown in Figure 2. 


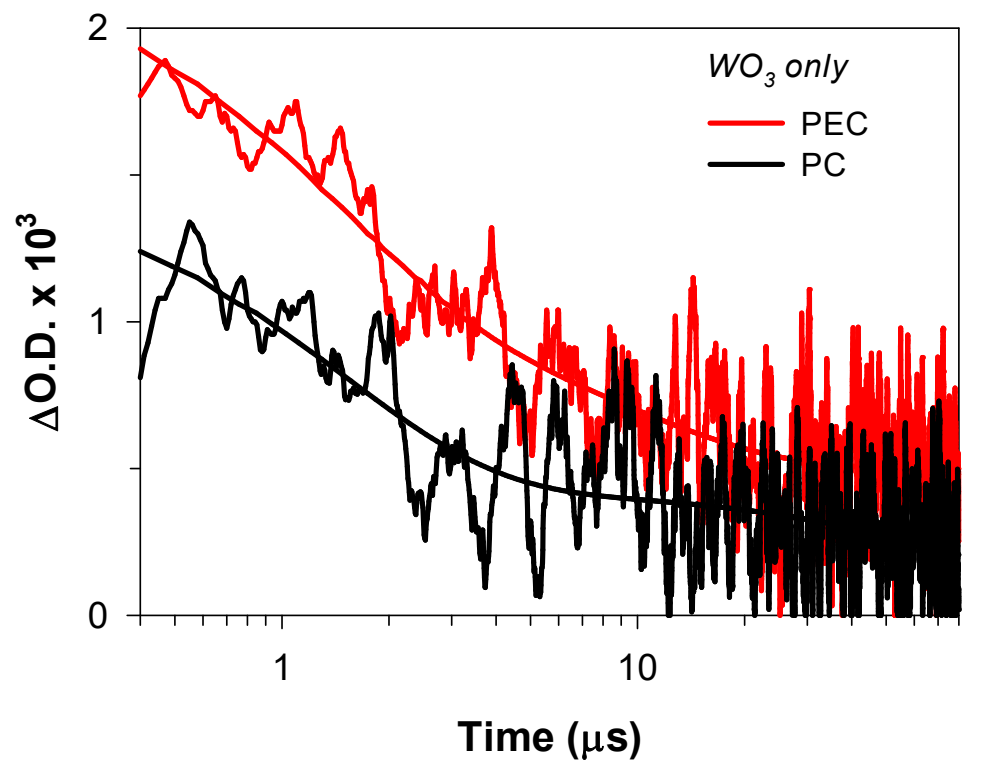

Figure S9. Transient absorption decay profiles of $\mathrm{WO}_{3}$ films in aqueous $\mathrm{NaNO}_{3}$ solutions $(0.5$ $\mathrm{M}$ ) at $\mathrm{pH} 3$ during PEC (biased at $1.88 \mathrm{~V}$ vs. RHE) and PC (bias-free) reactions at $450 \mathrm{~nm}$. 

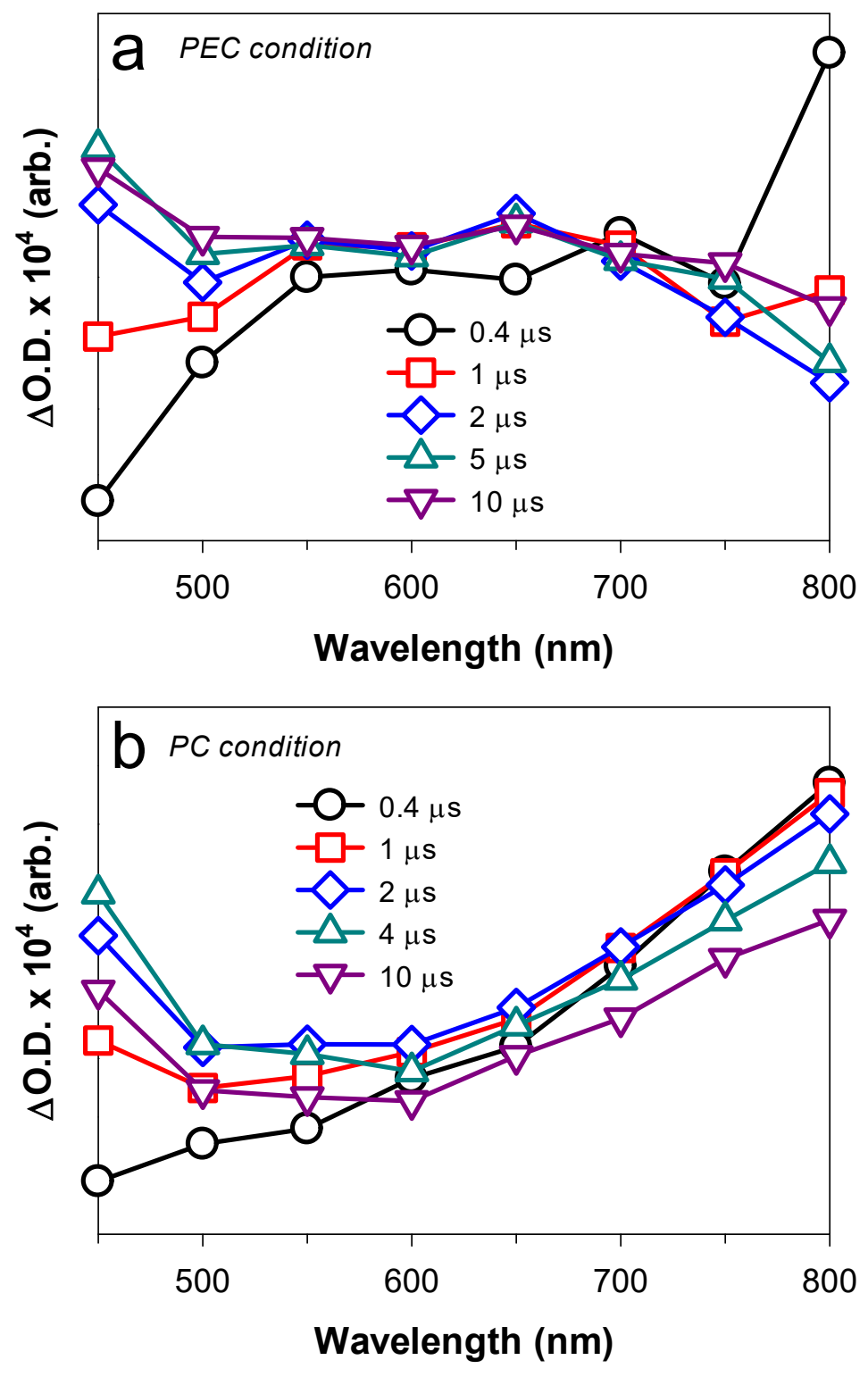

Figure S10. Time-resolved transient absorption spectra at different times under (a) PEC (E = $1.88 \mathrm{~V}$ vs. RHE) and (b) $\mathrm{PC}$ conditions in aqueous $\mathrm{NaNO}_{3}$ solutions $(0.5 \mathrm{M}, \mathrm{pH} 3)$. The spectra with $\mathrm{Fe}^{3+}$ were subtracted from those without $\mathrm{Fe}^{3+}$. 

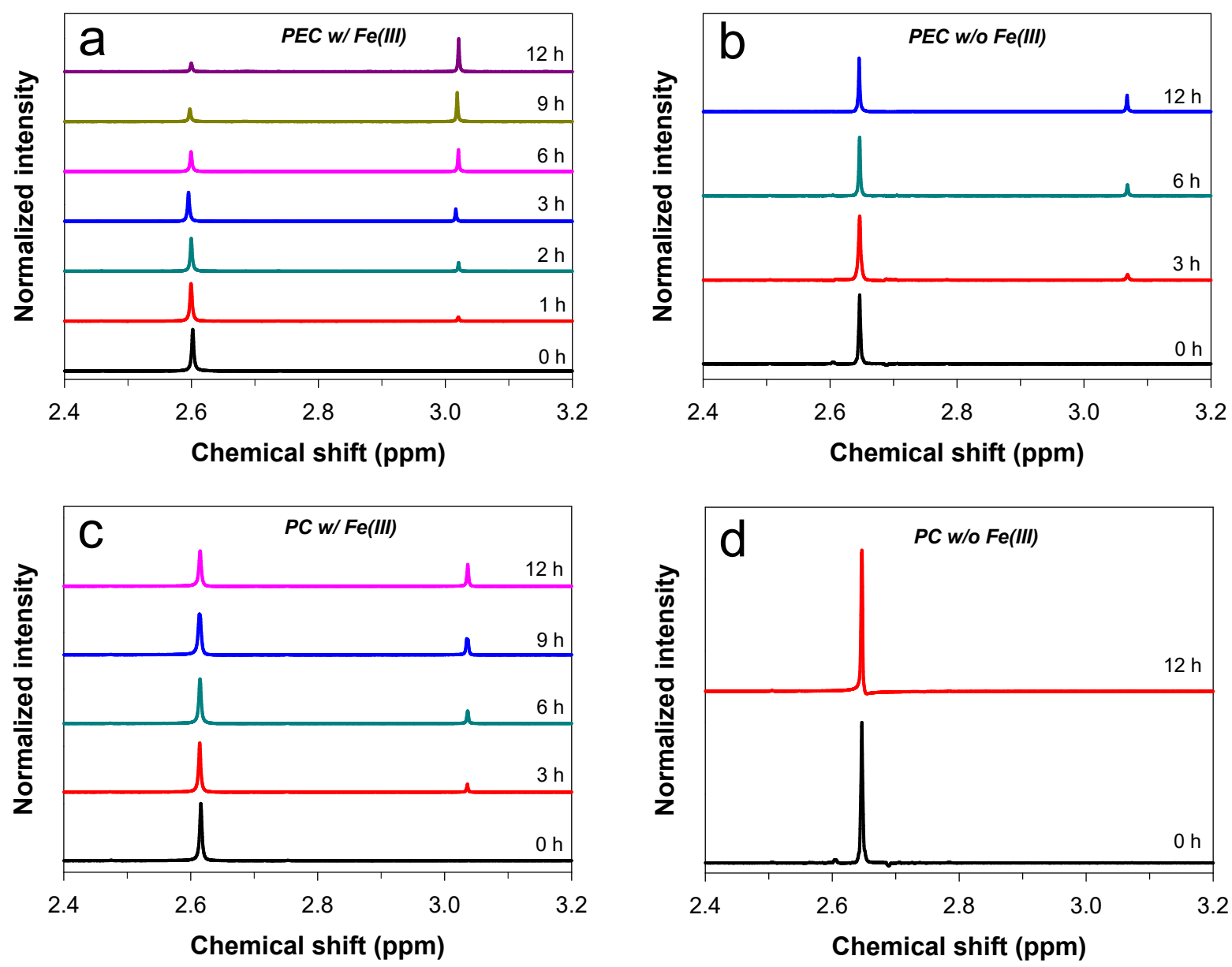

Figure S11. NMR spectra during (a and b) PEC reactions (a: with $\mathrm{Fe}(\mathrm{III})$, b: without $\mathrm{Fe}(\mathrm{III})$ ) and (c and d) PC reactions (c: with Fe(III)), d: without Fe(III)). The peak at 2.62 and 3.03 ppm represent DMSO and $\mathrm{DMSO}_{2}$, respectively. 

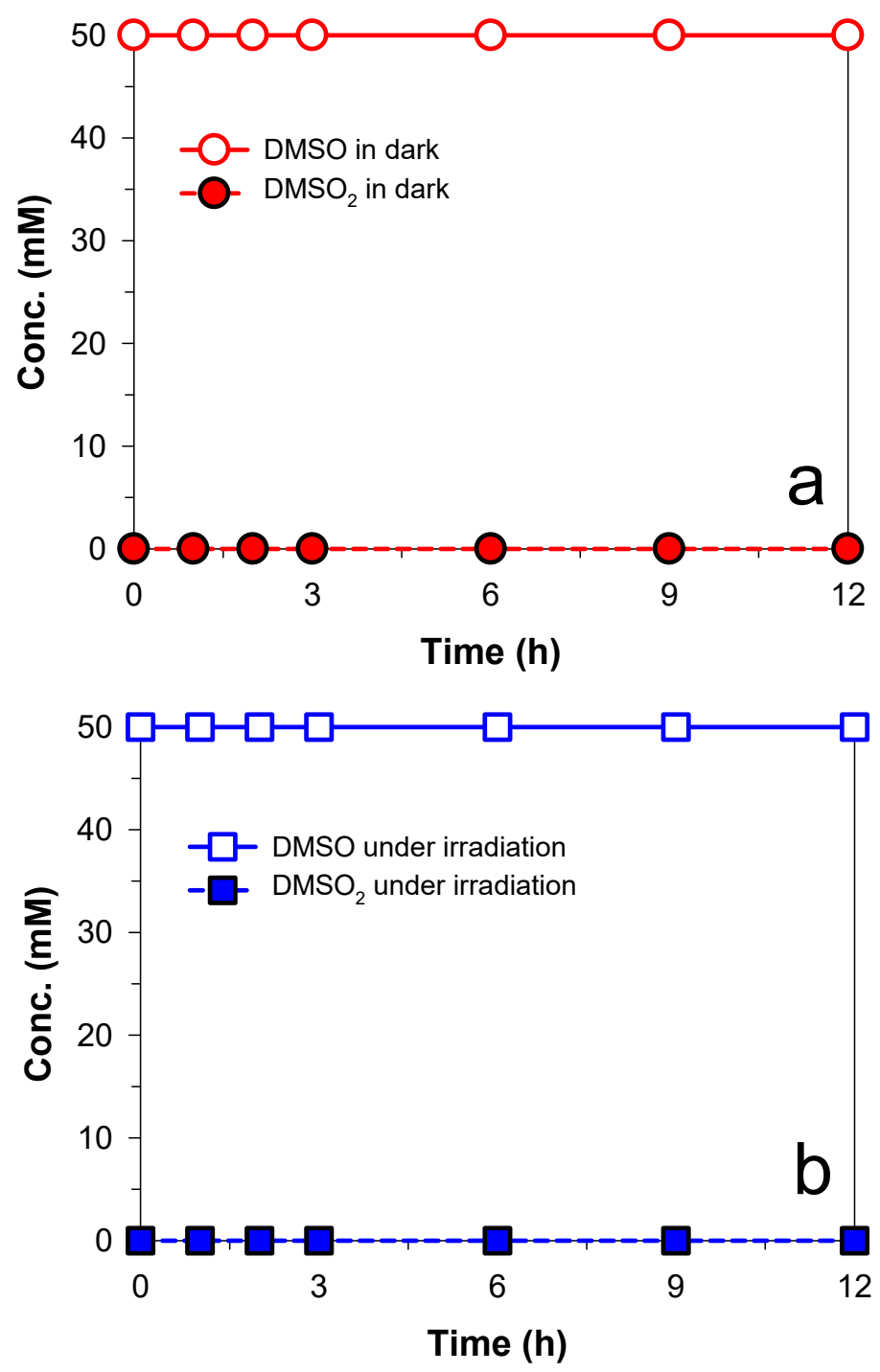

Figure S12. The oxidation of dimethyl sulfoxide (DMSO) and the concurrent production of dimethyl sulfone $\left(\mathrm{DMSO}_{2}\right)$ during the reactions with $50 \mathrm{mM} \mathrm{K}_{2} \mathrm{Fe}^{\mathrm{VI}} \mathrm{O}_{4}$ in aqueous $\mathrm{NaNO}_{3}$ solution $(0.5 \mathrm{M})$ at $\mathrm{pH} 3$ (a) in the dark or (b) under irradiation. To avoid the spectral interference from $\mathrm{H}_{2} \mathrm{O}$, all experiments were performed in deuterium oxide $\left(\mathrm{D}_{2} \mathrm{O}\right)$. Open and closed symbols represent DMSO and $\mathrm{DMSO}_{2}$, respectively. 

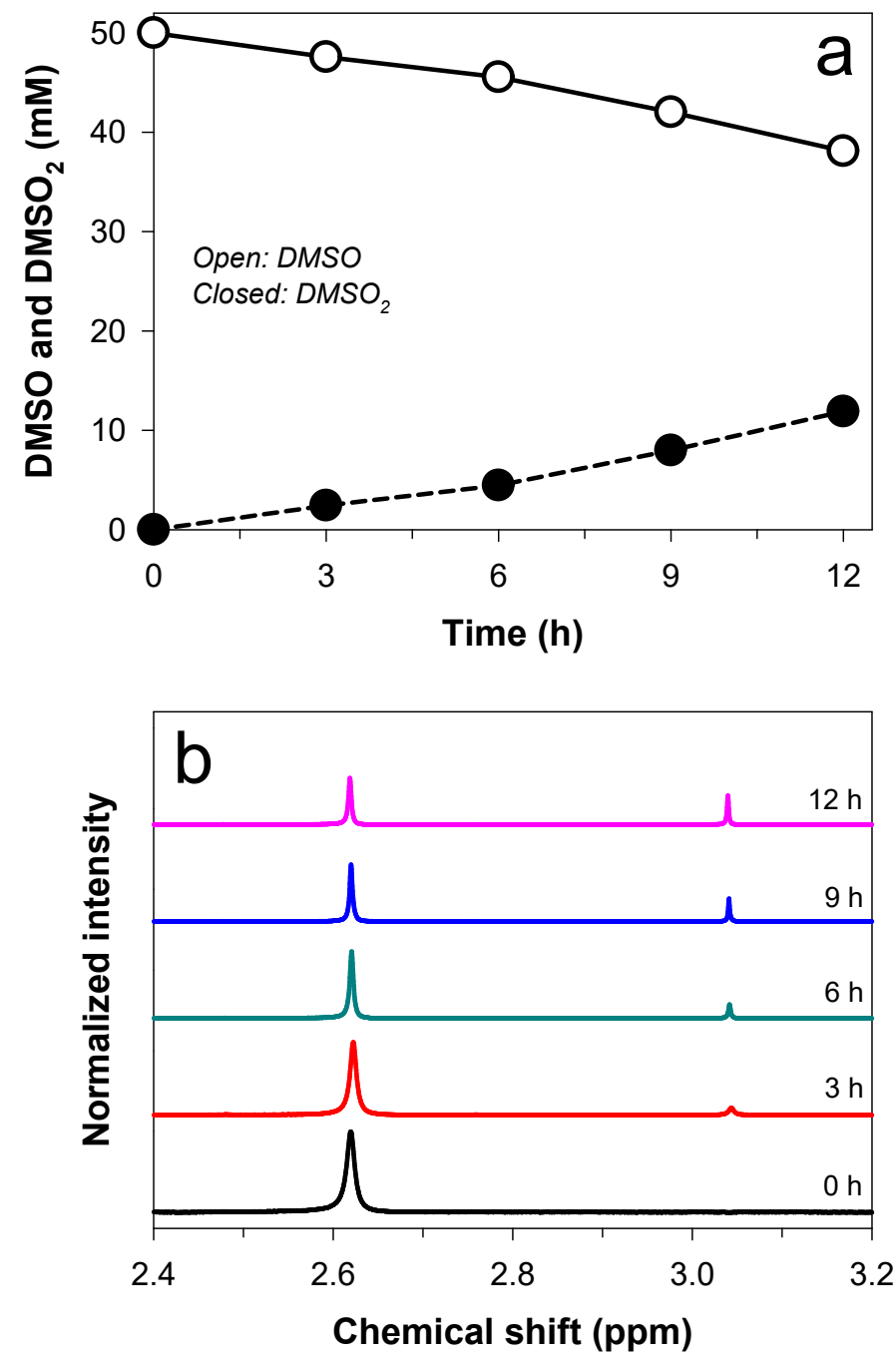

Figure S13. (a) The oxidation of dimethyl sulfoxide (DMSO) and the concurrent production of dimethyl sulfone $\left(\mathrm{DMSO}_{2}\right.$ ) during PEC (biased at $1.23 \mathrm{~V}_{\mathrm{RHE}}$ ) with $50 \mathrm{mM} \mathrm{Fe}^{2+}$. (b) $\mathrm{NMR}$ spectra during PEC reactions with $\mathrm{Fe}^{2+}$. The peak at 2.62 and $3.03 \mathrm{ppm}$ represent DMSO and $\mathrm{DMSO}_{2}$, respectively. 

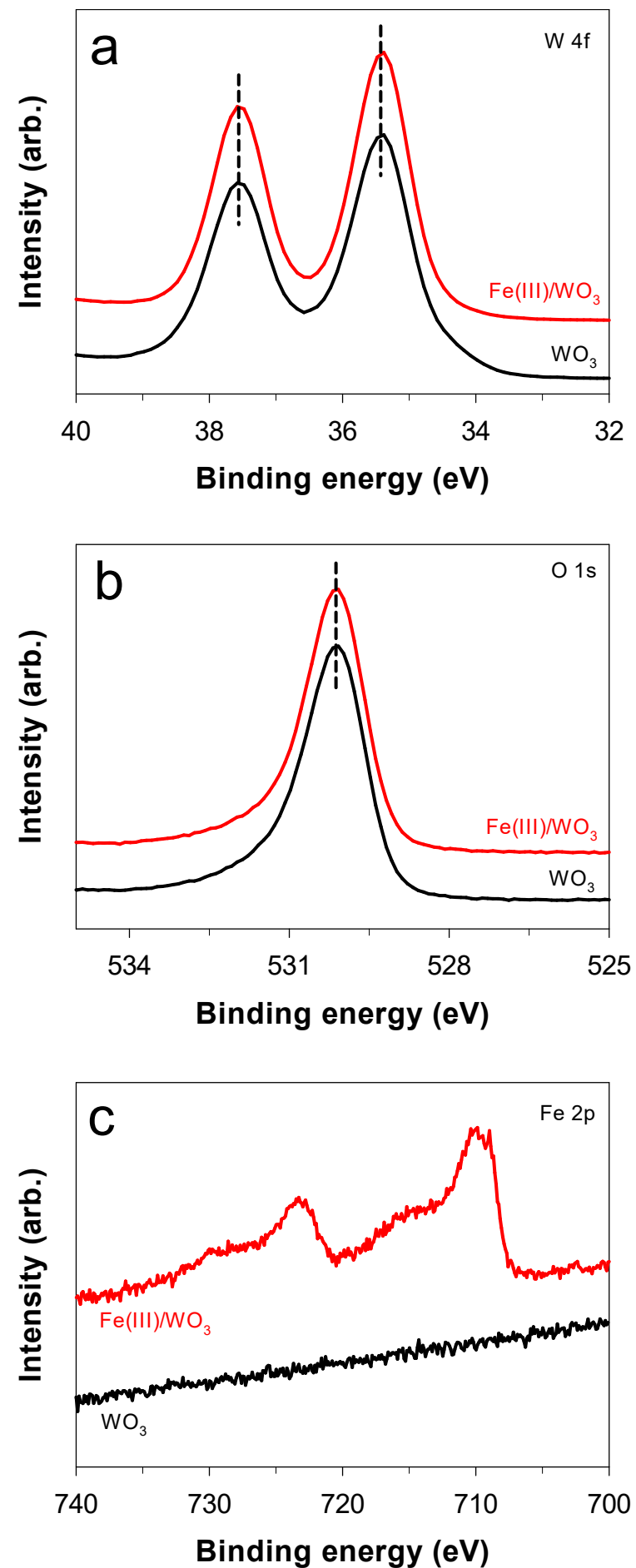

Figure S14. XPS spectra of $\mathrm{WO}_{3}$ (as-synthesized) and $\mathrm{Fe}(\mathrm{III}) / \mathrm{WO}_{3}$ (used in $\mathrm{PEC}$ reaction with $\mathrm{Fe}^{3+}$ ). (a) W 4f, (b) O 1s, and (c) Fe 2p. 

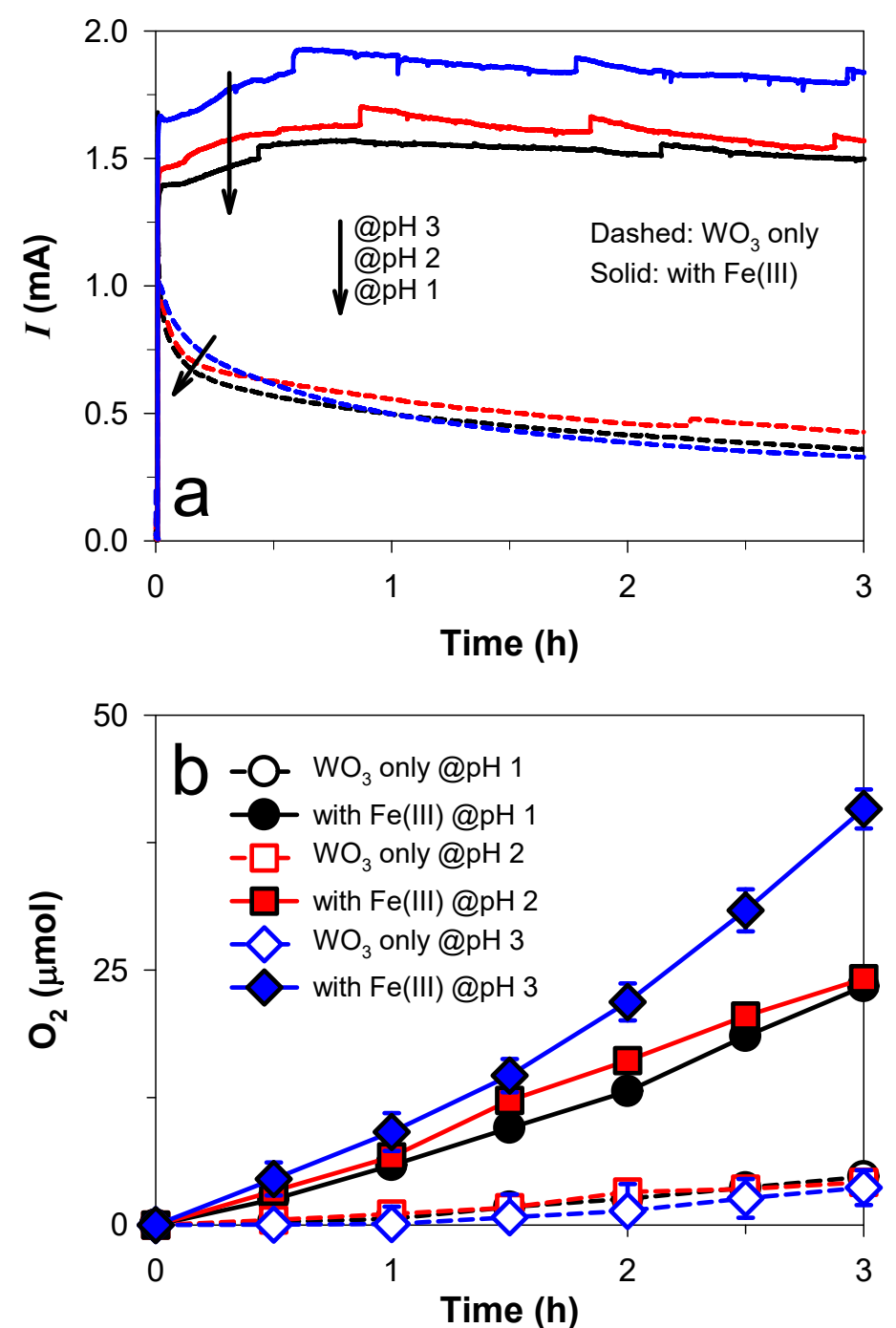

Figure S15. Photoelectrochemical water oxidation activities of $\mathrm{WO}_{3}$ films biased at $1.23 \mathrm{~V}$ RHE in aqueous $\mathrm{NaNO}_{3}$ solutions $(0.5 \mathrm{M})$ at different $\mathrm{pH}$ conditions in the absence and presence of $50 \mathrm{mM} \mathrm{Fe}^{3+}$. (a) Photocurrent-time profiles and (b) concurrent $\mathrm{O}_{2}$ evolutions. Faradaic efficiencies for $\mathrm{O}_{2}$ evolutions are shown in Figure 2. 


\section{References}

(1) Jeon, T. H.; Monllor-Satoca, D.; Moon, G. h.; Kim, W.; Kim, H. i.; Bahnemann, D. W.; Park, H.; Choi, W. Ag(I) ions working as a hole-transfer mediator in photoelectrocatalytic water oxidation on $\mathrm{WO}_{3}$ film. Nat. Commun. 2020, 11 (1), 967.

(2) Jeong, D.; Kim, K.; Min, D. W.; Choi, W., Freezing-enhanced dissolution of iron oxides: effects of inorganic acid anions. Environ. Sci. Technol. 2015, 49, 12816-12822. 